\title{
An Investigation of Effect of Tin (Sn) on Microstructures and Mechanical Properties of Gray Cast Iron
}

\author{
Recai KUS ${ }^{1}$, Bekir AKGUL ${ }^{2}$ \\ ${ }^{1}$ Selcuk University, Technology Faculty, Mechanical Engineering Dept. Konya Turkey \\ ${ }^{2}$ Selcuk University, Graduate School of Natural and Applied Sciences. Konya Turkey
}

\begin{abstract}
As the tensile strength of gray cast iron is low, it is tried to increase tensile strength by testing various alloying elements. The most preferred of these alloying elements was the copper element. However, it is known that copper increases both hardness and tensile strength by enhancing perlite ratio in microstructure. On the other hand, when tin (Sn) is used in trace amounts compared to copper, it has similar effects on hardness and tensile strength of cast iron.

In this study, adding tin element of 0,03-0,06-0,09-0,12-0,15\% by weight in gray cast iron, its effect on tensile strength was investigated and the appearance of the fracture surfaces was examined. It was compared with two different gray cast irons containing $0.4 \%$ copper element and free of alloying elements. According to the tensile strength results, the highest tensile strength was observed to be $195 \mathrm{~N} / \mathrm{mm} 2$ in the specimen number 6 containing $0,12 \% \mathrm{Sn}$. The lowest tensile strength was determined as $157 \mathrm{~N} / \mathrm{mm} 2$ in the specimen number 1 which did not contain alloying elements. In SEM (Scanning Electron Microscopy) images, it is seen that the samples generally exhibit a brittle rupture behaviour. In some of the specimens with the addition of tin and copper, regional ductile rupture behaviours were observed.
\end{abstract}

Key words: Gray Cat Iron, Tin (Sn), Tensile Strength, SEM

\section{INTRODUCTION}

In 1948, the first indication that tin in cast iron could cause significant changes in the microstructure was found by the Canadian Mining Office in Ottawa [1]. In the study, it was determined that perlite matrix in cast iron increased between 0,025-0,09 \% Sn with increasing tin ratio. In later studies, on the other hand, Morrogh revealed in 1952 that tin could be added up to $0.13 \%$ as a alloying element in cast iron [2]. There is a variety of literature about the effect of tin in cast iron with lamellar graphite on tensile strength. Although it has two different views, it is seen that tin has a positive effect on the tensile strength of gray cast iron. The tensile strength of gray cast iron increases continuously as the perlitic matrix structure in the microstructure increases [3]. The tensile strength of cast iron with lamellar graphite increases up to 0,20 and $0,30 \%$ tin
(Sn) and the tin quantities after these ratios decrease the tensile strength [4]. In another study, Veresh concluded that the tensile strength of gray cast iron decreased consistently as the tin content increased [5]. On the other hand, S. Dawson et al. showed in their study in 2001 that the addition of tin to cast iron increased Brinell hardness value and tensile strength concordantly [6]. In a study in 2007, Novytsky et al. reported that the tensile strength and hardness of cast iron increased in direct proportion to the perlite ratio of the matrix in the microstructure and the amount of perlite in the morphology increased with increasing amount of tin [7]. In another study, the addition of excessive amounts of tin (Sn) in vermicular cast iron widened the tendency of super cooling and some of the carbons in the melting system were solidified on the basis of metastability, while others were solidified as free cementite [8]. Shaban et al. showed that tin (Sn) increased compact graphite and graphite aspect ratio [9]. In their study in vermicular cast iron, Lyu et al.

Corresponding Author: Recai KUS, Selcuk University, Technology Faculty, Mechanical Engineering Dept. Konya Turkey 
found out that graphite size clearly decreased as tin (Sn) content increased between 0.003 and $0.057 \%$ by weight and an increase in tensile strength and impact toughness was obtained [10]. In a study on nodular cast iron by Lacaze et al., it's determined that tin rate was harmful after $0.05 \%$ [11].

In this study, the effect of tin on tensile strength was investigated experimentally by adding 5 different ratios $(0,03-0,06-0,09-0,12-0,15 \%)$ of tin $(\mathrm{Sn})$ to gray cast iron material and rupture surface analysis was performed after SEM images of rupture surfaces were taken.

\section{EXPERIMENT}

\section{Materials and Procedures}

The method chosen for this study is to produce tensile specimen in the sand molds in foundry conditions by applying different ratios of tin (Sn) and copper $(\mathrm{Cu})$. The produced specimens were tested by appropriate devices and the results were examined and evaluated.

For the study, a research specimen was produced in five different chemical compositions containing the reference sample and tin (Sn) in two different compositions. The first reference specimen does not contain copper and tin reinforcement. The second reference specimen contains copper additive but it does not contain tin. The other five research samples contain only tin alloy elements in different proportions. The amount of inoculation was determined as $0.04 \%$ by weight which was the standard for all specimens at the casting stage. The results of the chemical composition of the specimens are given in Table 1.. The amount of element $\mathrm{P}$ was $0.039 \%$. The amount of S element was $0,072 \%$.

Table 1: Spectral analysis.

\begin{tabular}{lllllll}
\hline $\begin{array}{l}\text { Spectral } \\
\text { Analysis }\end{array}$ & $\begin{array}{l}\mathbf{C} \\
(\boldsymbol{\%})\end{array}$ & $\begin{array}{l}\text { Si (\%) } \\
\text { (Furna } \\
\text { ce ) }\end{array}$ & $\begin{array}{l}\text { Si (\%) } \\
\text { (crucib } \\
\text { le) }\end{array}$ & $\begin{array}{l}\text { Mn } \\
(\%)\end{array}$ & $\begin{array}{l}\text { Cu } \\
(\%)\end{array}$ & $\begin{array}{l}\text { Sn } \\
(\%)\end{array}$ \\
\hline $\mathbf{1}$ Analloy & 3,47 & 1,65 & 1,81 & 0,46 & 0,06 & 0,001 \\
$\mathbf{2}(\mathbf{0 , 4}$ Cu) & 3,47 & 1,65 & 1,81 & 0,46 & 0,43 & 0,001 \\
$\mathbf{3 ( 0 , 0 3 ~ S n )}$ & 3,47 & 1,65 & 1,81 & 0,436 & 0,06 & 0,030 \\
$\mathbf{4 ( 0 , 0 6 ~ S n )}$ & 3,47 & 1,65 & 1,81 & 0,46 & 0,06 & 0,060 \\
$\mathbf{5 ( 0 , 0 9 ~ S n )}$ & 3,47 & 1,65 & 1,81 & 0,46 & 0,06 & 0,090 \\
$\mathbf{6 ( 0 , 1 2 ~ S n )}$ & 3,47 & 1,65 & 1,81 & 0,46 & 0,06 & 0,120 \\
$\mathbf{7 ( 0 , 1 5 ~ S n )}$ & 3,47 & 1,65 & 1,81 & 0,46 & 0,06 & 0,150 \\
\hline
\end{tabular}

30-kg small crucibles were used for casting the specimens. Alloying elements and inoculation materials were prepared precisely for $30 \mathrm{~kg}$ and put into the crucible before the molten metal was taken and casting was carried out by taking the liquid metal. The specimens which were brought to the standard dimensions for testing in the CNC bench were tested in the test equipment under the same conditions and the results were examined.

\section{Investigation of Tensile Strength}

Figure 1 shows the tensile specimen dimensions in accordance with the TSE EN ISO 6892-1: 2016 standard for gray cast iron with lamellar graphite

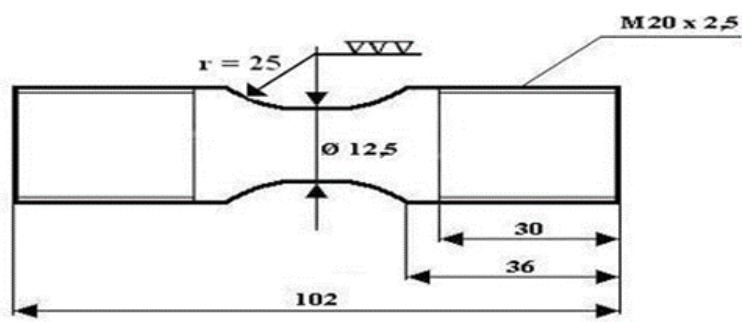

Fig. 1: Tensile specimen conforming to TSE EN ISO 6892-1: 2016 standards

\subsection{SEM Analysis}

The thermal fatigue test was done in a thermal cyclic furnace. The specimens were tested at $600^{\circ} \mathrm{C}$ highest temperature. Heating and cooling time were kept as 10 minutes. When the samples were cooled to the ambient temperature, they were taken out, dried and put into the high temperature furnace again, repeating the same process. More than $90 \%$ of the cracked regions of the surface of TBC systems were adapted as the criterion for the failure of the coating. The weight changes of the samples were measured to a precision of $0.5 \mathrm{mg}$ by an analytical balance. Three number of specimens were tested and average was considered for analysis.

\section{RESULTS AND DISCUSSION}

\subsection{Tensile Test Results}

The tensile test was carried out at Konya KOSGEB Service Directorate Laboratory with a dartec brand and 40 ton capacity tensile device. The tests of the specimens were carried out according to TSE ISO $6892 / 1$ test standards. The experiments were carried out at a tensile speed of $1 \mathrm{~mm} / \mathrm{min}$ at room temperature. Tensile test results of all samples are given in Table 2 .

Table 2: Tensile Test Results

\begin{tabular}{lcccc}
$\begin{array}{c}\text { Material } \\
\text { and } \\
\text { Properties }\end{array}$ & $\begin{array}{c}\text { Tensile } \\
\text { Strength } \\
\left(\mathbf{N} / \mathbf{m m}^{2}\right)\end{array}$ & $\begin{array}{c}\text { Yield } \\
\text { Strength } \\
\left(\mathbf{N} / \mathbf{m m}^{2}\right)\end{array}$ & $\begin{array}{c}\text { \% } \\
\text { Rupture } \\
\text { Elongati } \\
\text { on }\end{array}$ & $\begin{array}{c}\text { \% } \\
\text { Yield } \\
\text { Elonga } \\
\text { tion }\end{array}$ \\
\hline $\mathbf{1}[$ Analloyed] & 157 & 150 & 2,3 & 2,1 \\
$\mathbf{2}[\% 0,4 \mathrm{Cu}]$ & 177 & 173 & 2,7 & 2,6 \\
$\mathbf{3}[\% 0,03 \mathrm{Sn}]$ & 166 & 162 & 2,5 & 2,3 \\
$\mathbf{4}[\% 0,06 \mathrm{Sn}]$ & 176 & 167 & 2,6 & 2,2 \\
$\mathbf{5}[\% 0,09 \mathrm{Sn}]$ & 185 & 180 & 2,8 & 2,6 \\
$\mathbf{6}[\% 0,12 \mathrm{Sn}]$ & 195 & 190 & 2,8 & 2,7 \\
$\mathbf{7}[\% 0,15 \mathrm{Sn}]$ & 175 & 168 & 2,55 & 2,2 \\
\hline
\end{tabular}


All of the specimens exhibited a brittle rupture character. The number 1 reference specimen which did not contain alloying element showed an elongation of $2.3 \%$ and a tensile strength of $157 \mathrm{~N} / \mathrm{mm}^{2}$. The specimen containing $0.4 \% \mathrm{Cu}$ showed $2.7 \%$ elongation and $177 \mathrm{~N} / \mathrm{mm}^{2}$ tensile strength.

The tin element increased the tensile strength of gray cast iron up to $0.15 \%$ Sn in every increase $(0.03 \%, 0.06 \%, 0.09 \%, 0.12 \%)$. The value of $0.12 \%$ sn gave the highest tensile strength for cast iron. After this value, a decrease was observed every $0.15 \% \mathrm{Sn}$. The best and most efficient results were obtained in the sample containing $0.12 \% \mathrm{Sn}$. The tensile strength was determined as $195 \mathrm{~N} / \mathrm{mm}^{2}$ and the elongation at break was $2.8 \%$. It has the highest tensile strength among the specimens. The sample with the highest tin ratio shows a decrease in tensile strength and elongation at break.

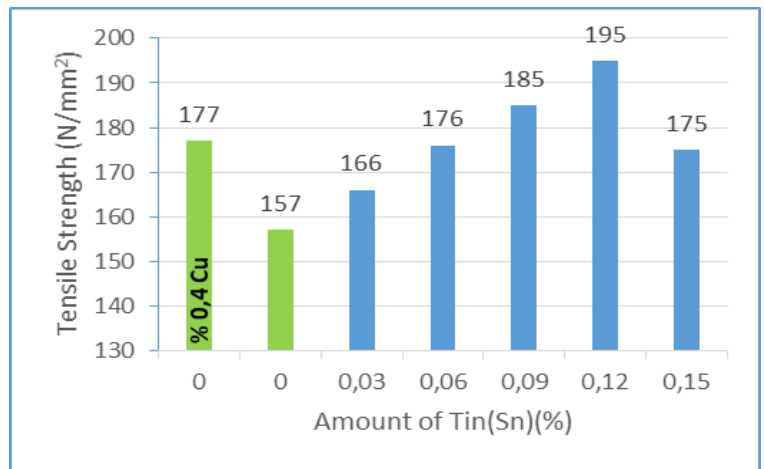

Fig. 2: Tensile strength results

The tensile stress of the specimen containing $0.15 \% \mathrm{Sn}$ was $175 \mathrm{~N} / \mathrm{mm}^{2}$ and the elongation at break was $2.55 \%$.

As shown in the graphical curves between Figures 3 and 9, the specimens did not show a significant yield. To find the yield strength, the point cut by the line drawn parallel to the curve from the $0.2 \%$ elongation value in the curve was determined as yield.

Although the results in this study did not match the results of Prytherch, it was stated that tin could increase the tensile strength of gray cast iron. In another study conducted in 1969, Thwaites emphasized that the tensile strength increased in parallel with the increase in the perlite amount in the microstructure and perlite ratio in gray cast iron could increase with the addition of tin element. The results of Thawaites correspond to this study and support Thawaites.

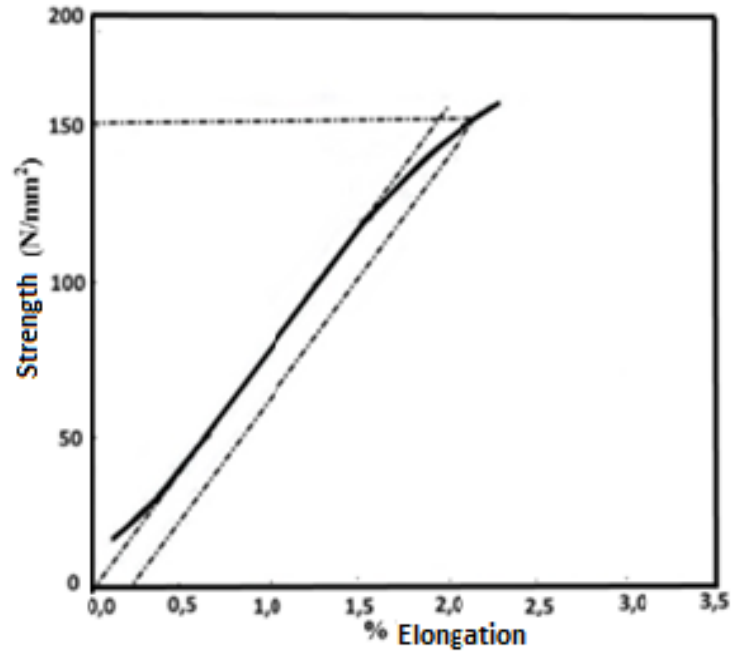

Fig. 3: Tensile curve of reference specimen without

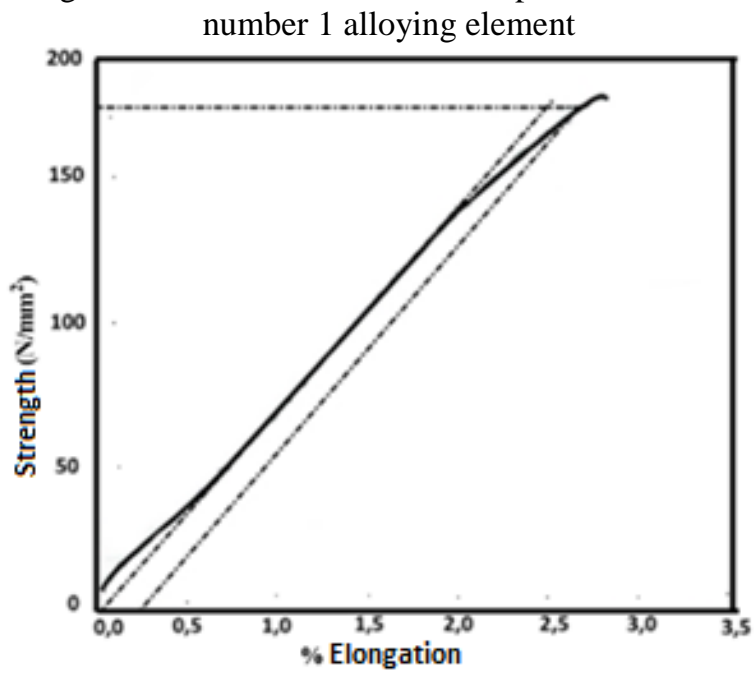

Fig. 4: Tensile curve of number 2 specimen containing

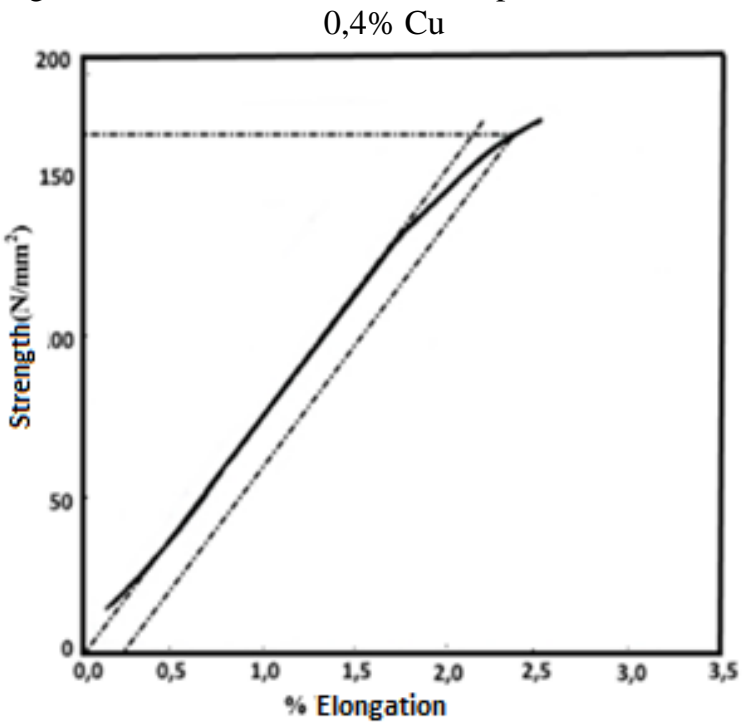

Fig. 5:Tensile curve of number 3 specimen containing $0,03 \% \mathrm{Sn}$ 


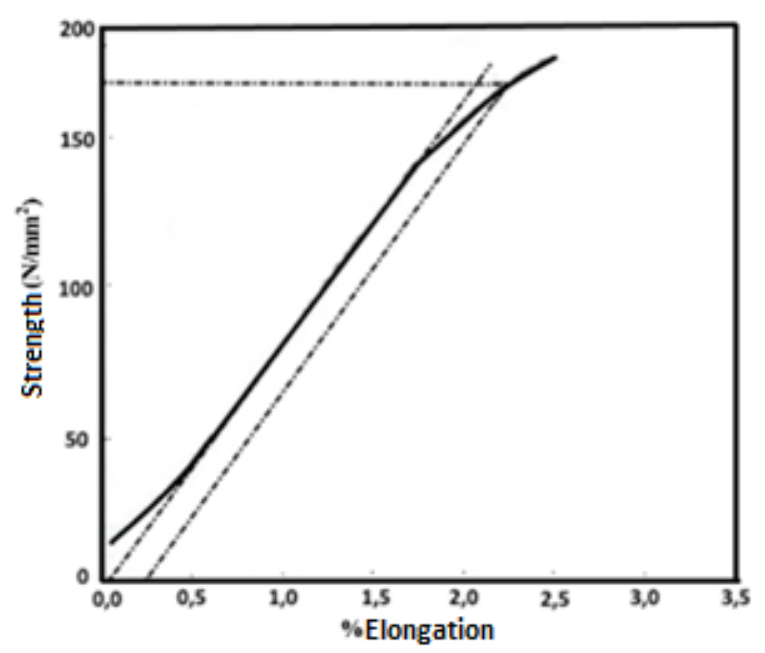

Fig. 6: Tensile curve of number 4 specimen containing

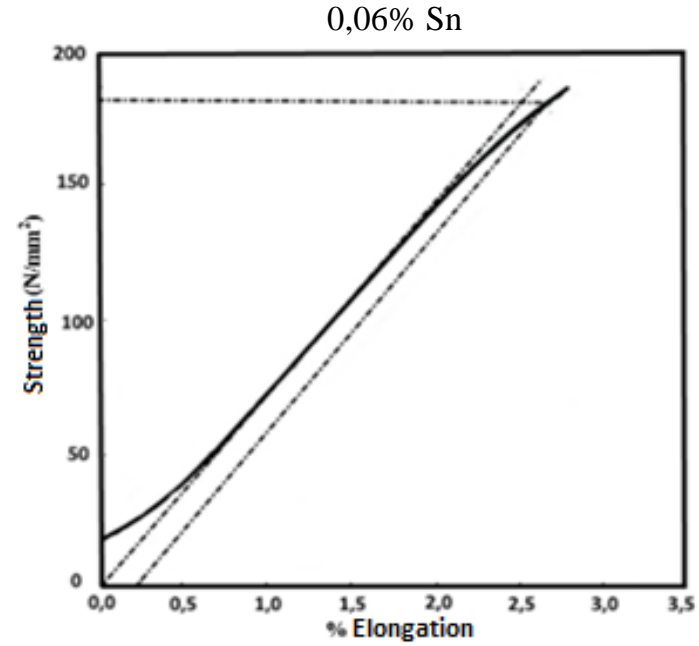

Fig. 7: Tensile curve of number 5 specimen containing $0,09 \% \mathrm{Sn}$

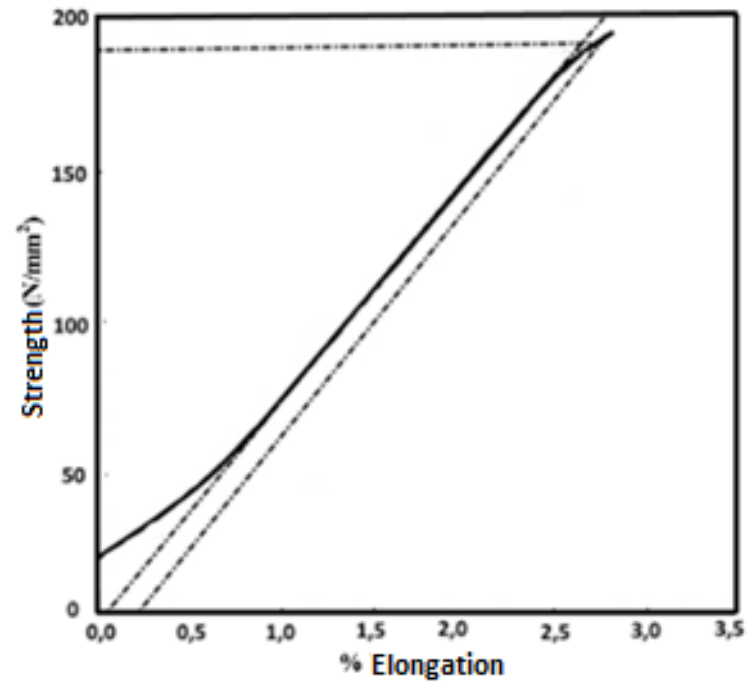

Fig. 8: Tensile curve of number 6 specimen containing $0,12 \% \mathrm{Sn}$

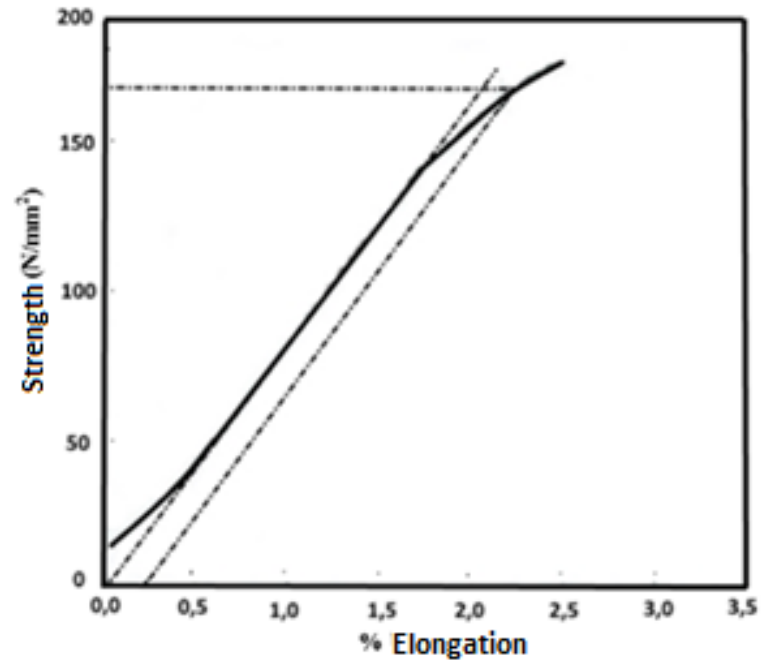

Fig. 9:Tensile curve of number 7 specimen containing $0,15 \% \mathrm{Sn}$

\subsection{SEM Analysis Results}

When we look at the images of 7 different samples at SEM at 100X magnification, the general rupture behaviour is brittle. It was found that the general rupture and the regional rupture behaviour were completely brittle in the specimen without alloying element. The planes of the lamellae on the rupture surface and the sample being broken from the lamella planes are shown in Figure 10. This reveals that the lamellae have a notch effect on the material. On the rupture surface of the specimen with the addition of copper $(0.4 \%)$ element, lamella planes were less common than the unalloyed sample. The general rupture behaviour is brittle, but in some regions it has exhibited ductile rupture compared to the unalloyed specimen. It is possible to see the notch effect of the lamellae here (Figure 11). A similar image to the specimen without alloying element was obtained in SEM image of specimen containing $0.03 \%$ tin element. As seen in Figure 12, the general rupture is brittle. Traces of ductile rupture are seen even a little in rare regions. Lamella planes and the notch effect lamellae are also seen here. The rupture image of the specimen containing $0.06 \% \mathrm{Sn}$ in Figure 13 is generally brittle. Compared to the reference specimen without alloying element, ductile rupture planes are seen in more regions. As seen in Figure 13, lamella planes and the notch effect of the lamellae in the structure were observed. The rupture surface of the specimen containing $0.09 \% \mathrm{Sn}$ is generally brittle but it is higher in regional ductile ruptures compared to the specimens containing $0.06 \% \mathrm{Sn}$ and $0.4 \% \mathrm{Cu}$. The tensile strength value also supports this image. The lamella planes in rupture surface in the image of Figure 14 show the notch effect of the lamellae. General rupture behaviour of rupture surface of the specimen in Figure 15, which had maximum tensile strength result and contained 
$0,12 \mathrm{Sn} \%$, was brittle. In spite of this, more regions with ductile rupture behaviours were observed in this specimen than the other specimens. Lamella planes and the notch effect of the lamellae are also seen here. other samples.

Figure 16 shows the rupture surface image of the specimen containing $0.15 \%$ tin element. General and regional rupture behaviour on rupture surface was observed to be brittle. A similar rupture is seen when regional ductile rupture is compared to the specimen without alloying element. Rupture planes and notch effect of the lamellae within the structure are clearly seen in this specimen.

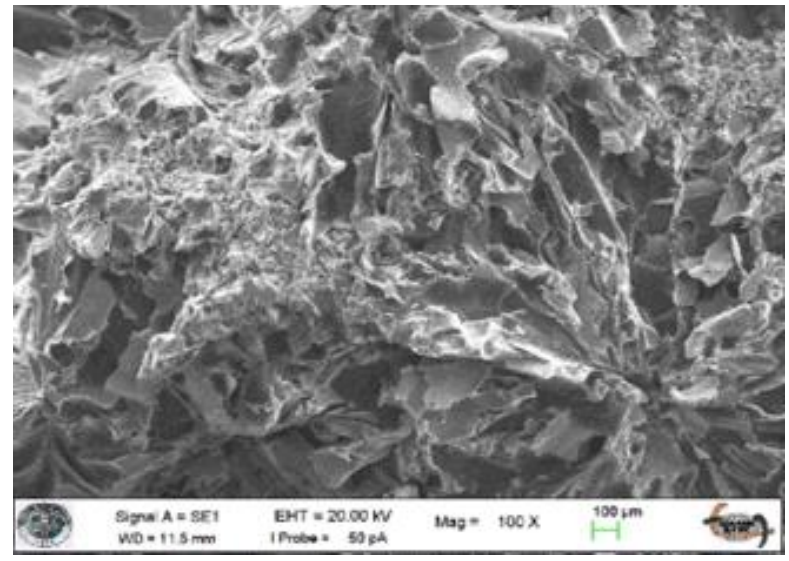

Fig. 10: SEM image of the rupture surface of the number 1 specimen containing the alloying element at $100 \mathrm{X}$ magnification

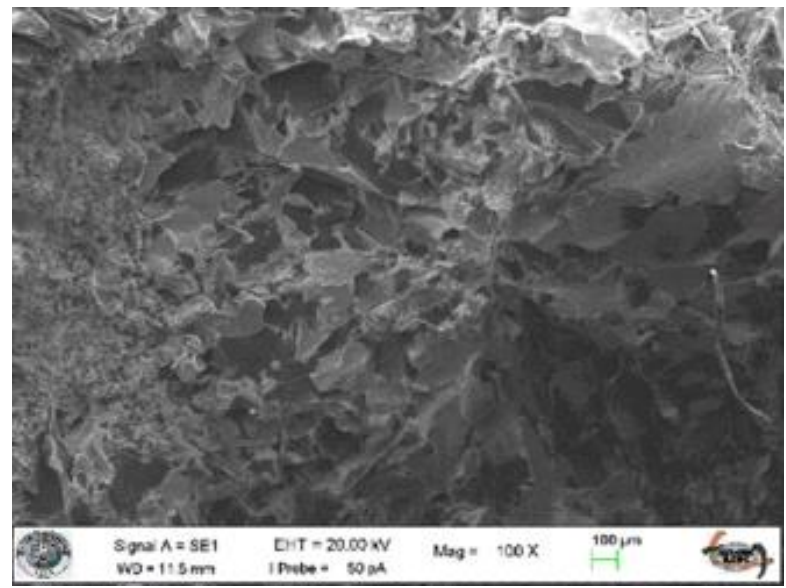

Fig. 11: SEM image of the rupture surface of the number 2 specimen containing $0,4 \% \mathrm{Cu}$ at $100 \mathrm{X}$ magnification

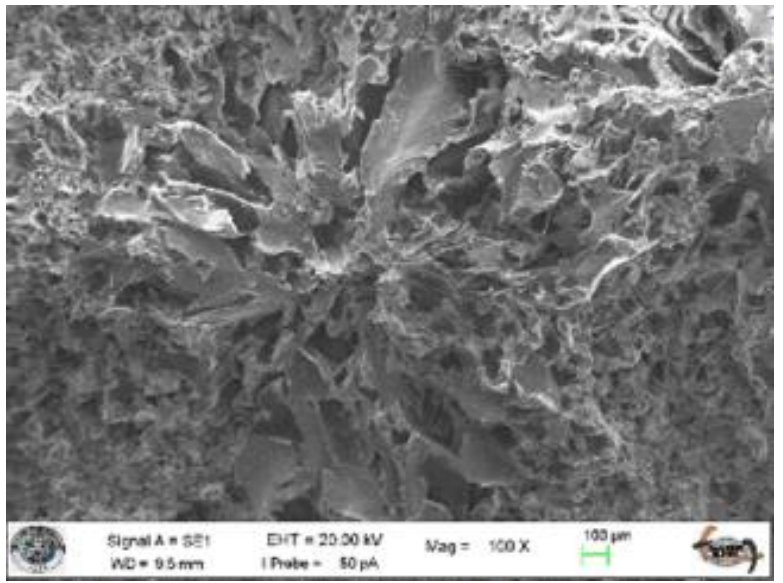

Figure 12: SEM image of the rupture surface of the number 3 specimen containing $0,03 \% \mathrm{Sn}$ at $100 \mathrm{X}$ magnification

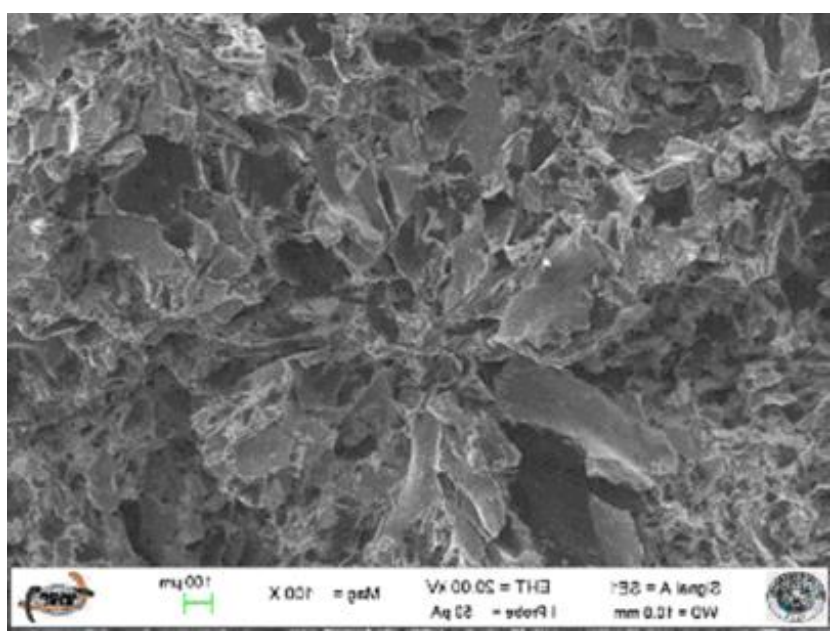

Fig. 13: SEM image of the rupture surface of the number 4 specimen containing $0,06 \% \mathrm{Sn}$ at $100 \mathrm{X}$ magnification

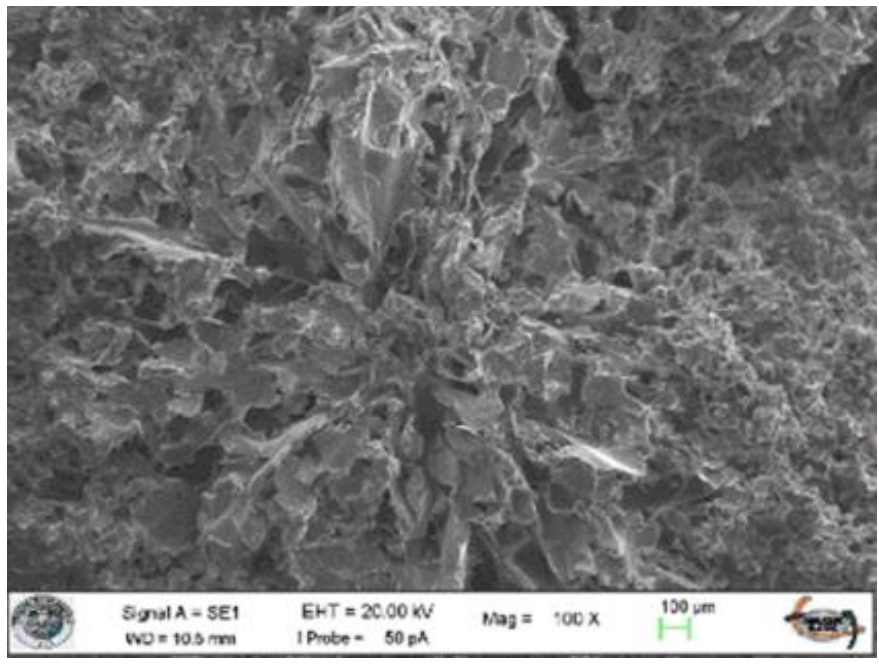

Fig. 14: SEM image of the rupture surface of the number 5 specimen containing $0,09 \% \mathrm{Sn}$ at $100 \mathrm{X}$ magnification 


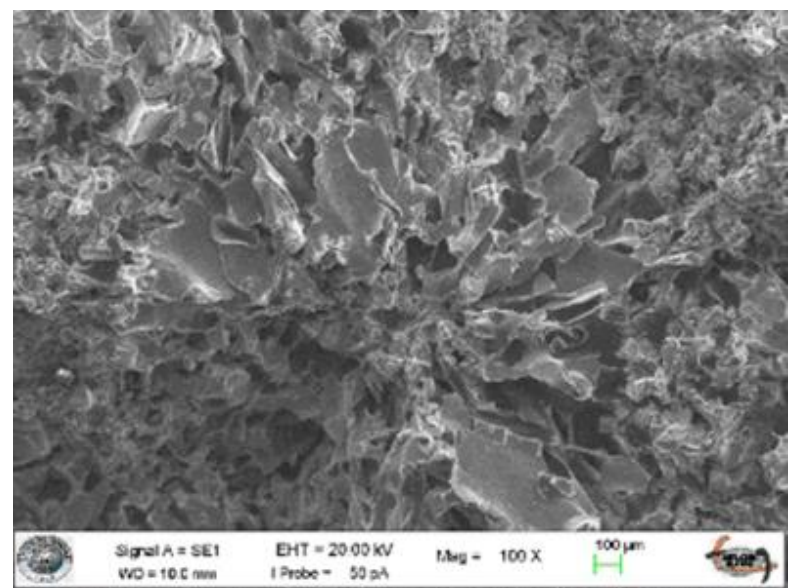

Fig. 15: SEM image of the rupture surface of the number 6 specimen containing $0,12 \% \mathrm{Sn}$ at $100 \mathrm{X}$ magnification

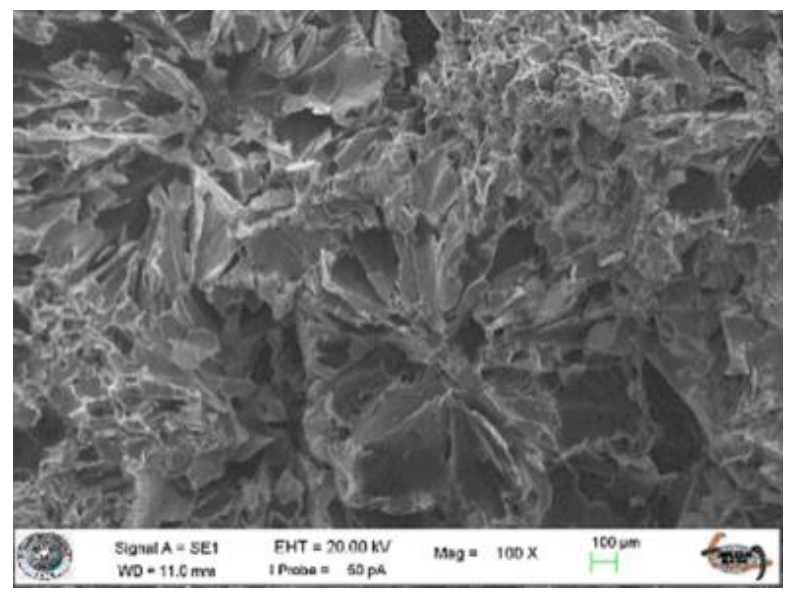

Fig. 16: SEM image of the rupture surface of the number 7 specimen containing $0,15 \% \mathrm{Sn}$ at $100 \mathrm{X}$ magnification

\section{CONCLUSIONS}

When the tensile test results were examined in the study, the lowest tensile strength was determined as $157 \mathrm{~N} / \mathrm{mm}^{2}$ in the reference specimen without alloying element. It was $177 \mathrm{~N} / \mathrm{mm}^{2}$ in another reference specimen containing $0.4 \% \mathrm{Cu}$ element. The closest tensile strength to this specimen containing copper element was found to be $176 \mathrm{~N} / \mathrm{mm}^{2}$ in the specimen containing $0.06 \% \mathrm{Sn}$. It increased in the specimens when tensile strength values contained $0.09 \%$ and $0.12 \%$ tin $(\mathrm{Sn})$ elements.

A decrease was observed in tensile strength of the specimen containing $0.15 \% \mathrm{Sn}$. It is thought that tensile strength decreases because the structure morphology in the sample containing $0,15 \% \mathrm{Sn}$ reaches saturation in perlite amount and could be more precipitated as graphite.

SEM analyzes of the tensile test rupture surfaces of the specimens reveal the notch effect of the lamellae in the structure. The lamella planes are also seen with SEM analysis. Tensile strength was low in specimens with high lamella plane. The regional brittle rupture was observed in some regions in specimens containing tin element. It can be said that tin element has a positive effect on the tensile strength of gray cast iron. However, it should be noted that this effect is up to a certain percentage. This was stated as $\% 0,057 \mathrm{Sn}$ or $\% 0,1 \mathrm{Sn}$ in some sources in the literature. In our study, the max $\mathrm{Sn}$ value was observed as $0.12 \%$.

\section{Recommendations}

$\checkmark \quad$ In gray cast iron, it could be more suitable to add tin in the crucible for alloying efficiency. Some losses are seen when it is carried out in furnace.

$\checkmark$ Better tensile strength can be achieved if the produced samples are heat treated such as normalization or tempering.

$\checkmark$ The casting of tensile specimens can be carried out with ceramic shell investment method. Thus, the formation of oxide can be prevented by casting into the heated ceramic mold and cooling can be more normal.

$\checkmark$ Increasing the addition of tin in gray cast iron, the results can be observed.

\section{ACKNOWLEDGMENTS}

The data in this paper were benefited from MSc. thesis studies of Bekir AKGUL. The authors acknowledge the support provided by the Scientific Research Projects Coordinatorship of Selcuk University Contract No:17201061.

\section{REFERENCES}

[1] Rehder, J. E., 1948, A Cause of Poor Anneal ability of a Commercial Malleable Iron, Canadian Metals and Metallurgical Industries, 11, 20-21.

[2] Morrogh, H., 1952, The Harmful Influence of Some Residual Elements in Magnesium - Treated Nodular Cast Irons and Their Neutralization by Cerium, B.C.I.R.A. Journal, 4, 292-314.

[3] Thwaites, C. J., 1969, The Development of the Use of Tin to Improve the Quality of Iron Castings, Iron and Steel, 42, 201-208.

[4] Prytherch, C. J. T. a. J. C., 1969, 'Structural Stability of Flake-graphite Iron Alloyed with Tin and Chromium, Foundry Trade Journal, 126, 115121.

[5] Veresh, L. I. L. a. A., 1967, Influence of Tin on the Structure and Properties of Gray Iron, Russian Castings Production, 7, 338-340.

[6] S. Dawson, M. R., U. Reuter, 2001, The Effect of Metallurgical Variables on the Machinability of Compacted Graphite Iron, Society of Automotive Engineers Inc. 
[7] V. G. Novytskyy, V. P. H., and D. D. Panasenko, July, 2007, Effect of Tin on The Wear Resistance and Secondary Structure of Cast Composites of The $\mathrm{Fe}-\mathrm{Cr}-\mathrm{Cu}-\mathrm{Ti}-\mathrm{C}$ System Under Sliding Friction, Metallovedenie $i$ Termicheskaya Obrabotka Metallov, 49, 22.

[8] Y. C. Peng, H. J. J., J. H. Liu and G. L. Li, 2012, Mater. Charact, 72, 53-58.

[9] M. Shaban, A. M., A. Halvaee and J. Rassizadehghani, 2013, Effect of Si content and Sn addition on solidification behavior and graphite morphology of compacted graphite iron, Academic Research Online Publisher Sdn. Bhd., 1 (2), 87100.

[10] Lyu Y., Y. S., S. Liu and J. Zhao, July 2015, Effect of tin on microstructure and mechanical properties of compacted graphite iron, Article in International Journal of Cast Metals Research, 0 (0).

[11] Lacaze, J. a. S., Jon, 2017, Effect of Tin on The Phase Transformations of Cast Irons, Journal of Phase Equilibria and Diffusion, pp. 1-7. 